\title{
ANALISA PENGARUH LOG TRANSAKSI PADA SISTEM KOMPUTER MENGGUNAKAN ALGORITMA RECOVERY BERBASIS LOG
}

\author{
Fricles Ariwisanto Sianturi \\ Manajemen Informatika \\ STMIK Pelita Nusantara, Jl.Iskandar Muda No.1 Medan, Sumatera Utara, 20154 Indonesia \\ sianturifricles@gmail.com
}

\begin{abstract}
This study aims to melakukakan analysis of the effect of the transaction log on a computer based system either on a single system tired, and two tiered through simulated transactions bank system with technology client / server to get a log of transactions on the database system Microsoft Windows SQL Server 2008 R2 management studio a data base. Methods or algorithms are used to analyze the transaction log on the system used is a log-based recovery algorithm. The results based on the analysis, showed that the use of query local database and query the database using sotere procedure to get the transaction log for troubleshooting transactions on the database system via a user interface is built to help job database administrator (DBA), much more good compared with conventional systems. Based on the experiments that the log of transactions to be controlled, in-undo, Re-do, or Rolled-Back, even deleted if no longer required automatically to maintain the scalability of computer users in the future, by setting the growth of a standard database from $10 \%$ to $>$ $32 \%$, and the establishment of a maintenance schedule to ensure that the reserve database is always available and up to date.
\end{abstract}

Keywords : transaction log analysis, computer-based systems, simulated bank system, client / server twotiered, SQL Server database.

\begin{abstract}
Abstrak
Penelitian ini bertujuan untuk melakukakan analisa pengaruh log transaksi pada sistem berbasis komputer baik pada sistem single tired, maupun two tiered melalui simulasi transaksi sistem bank dengan teknologi client/server untuk mendapatkan log transaksi-transaksi pada sistem basis data microsoft windows SQL Server 2008 R2 management studio sebagai pangkalan datanya (Database).

Metode atau algoritma yang digunakan untuk menganalisa log transaksi pada sistem yang digunakan adalah algoritma recovery berbasis $\log (\log$-Based Recovery Algorithm). Hasil penelitian berdasarkan analisis, menunjukkan bahwa menggunakan query basisdata lokal dan query basis data menggunakan sotere procedure untuk mendapatkan log transaksi untuk mengatasi masalah transaksi pada sistem basis data melalui antarmuka pengguna (user interface) yang dibangun dapat membantu pekerjaan database administrator (DBA), jauh lebih baik dibandingkan dengan sistem konvensional. Berdasarkan percobaan bahwa log dari transaksi-transaksi harus dikendalikan, di-undo, Re-do, atau di Rolled-Back, bahkan juga dihapus jika tidak diperlukan lagi secara otomatis untuk menjaga skalabilitas pengguna komputer dimasa yang akan datang, dengan mensetting pertumbuhan basis data standar dari $10 \%$ menjadi $>32 \%$, dan penetapan jadwal pemeliharaan untuk memastikan bahwa cadangan (backup) basis data selalu ada dan terkini
\end{abstract}

Kata Kunci: Analisa log transkasi, sistem berbasis komputer, simulasi system bank, client/ server 2-tiered, basis data SQL Server.

\section{PENDAHULUAN}

Setelah menyelesaikan rancangan desain basisdata, membuat program aplikasinya serta proses instalasi dan konfigurasi terhadap database server/client, setiap administrator basisdata dapat beristirahat. Tetapi, hal penting yang harus diingat bahwa proses administrasi tidak berakhir walaupun basisdata tersedia secara lancar untuk melayani kebutuhan permintaan. Harus dipertimbangkan banyak hal selama perancangan basisdata, yaitu : Unjuk kerja, kendali akses - kendali akses, strategi Backup, pengendalian transaksi-transaksi log, normalisasi dan pengindeksan. Sudakah kita mengambil waktu untuk mengembangkan rencana kontigensi untuk mengantisipasi kemungkinan beberapa hal yang mungkin akan mempengaruhi basis data dimasa yang akan datang.

Pemulihan dari kondisi kegagalan seringkali diabaikan sehingga penanganannya akan terlambat ketika sudah terjadi. Administrator-administrator basis data yang sibuk dengan mudahnya meremehkan tugas ini dan berjanji akan membenahi transaksi log dan cadangan basis data yang benar setelah menyelesaikan proyek yang besar ini dan itu. Perlu dipertimbangkan nilai data dari perusahaan. Apa akibatnya jika waktu yang berharga dari perubahan basisdata yang kemudian hilang sehari?, Bagaimana dengan kehilangan keseluruhan dari basis data? 
Kebanyakan jawaban yang serupa untuk menjawab pertanyaan tersebut adalah sebuah rencana yang komprehensif untuk pemulihan dari kondisi kegagalan atau gagalnya server(Server Down). Mereka juga akan membentuk kondisi awal dari rencana pengembangan spesifik terhadap kebutuhan perusahaan. Dua mekanisme pemulihan dari kondisi kegagalan yang ditawarkan oleh basidata(Microsoft SQL Server) yaitu cadangan basisdata(database backups) dan catatan transaksi (transaction logs).

Model-model rancangan perantara antar muka pengguna akan sangat mebantu untuk memudahkan sebahagian dari pekerjaan tersebut khususnya pada system berbasis komputer, sehingga menambah kwalitas kerja administrator dalam menangani setiap permasalahan yang timbul baik pada kondisi sebelum ada masalah dan setelah ada masalah, berdasarkan latar belakang inilah peneliti ingin membuat judul penelitian "Analisa Pengaruh Log Transaksi Pada Sistem Berbasis Komputer Menggunakan Algoritma Recovery Berbasis Log", [ Johnson, Eric J].

\section{TINJAUAN PUSTAKA}

DBMS membuat suatu versi record baru yang berisi overwriting dari record yang lama, dengan mekanisme ini transaksi read only dapat berjalan secara konkuren dengan transaksi update, tanpa kehilangan konsistensi dari basis data. Sedangkan mekanisme hybrid merupakan kombinasi antara ketiga mekanisme tersebut.

\subsection{Sistem Recovery}

Sebuah sistem komputer, sama seperti peralatan lainnya, adalah merupakan subjek yang akan mengalami kegagalan dari berbagai penyebab, seperti :

a. disk crash,

b. kegagalan power,

c. software error,

d. terbakarnya ruangan komputer,

e. dan sabotase.

Pada setiap kegagalan dapat menyebabkab hilangnya data. Namun demikian, sistem database harus bertindak untuk memastikan bahwa atomicity dan durability transaksi dapat dipertahankan, Suatu bagian integral dari sistem database adalah rencana penyembuhan yang dapat merestore database kestate yang konsisten, eksis sebagaimana sebelum mengalami kegagalan. Rencana penyembuhan juga harus menyediakan kemampuan tinggi, mampu meminimumkan waktu dimana database tidak dapat dipakai setelah crash.

\subsection{Klasifikasi Kegagalan}

Ada beberapa jenis kegagalan yang dapat terjadi pada sistem, masing-masing perlu dihadapi dengan suatu cara yang berbeda. Tipe kegagalan yang paling sederhana tidak menyebabkan kehilangan informasi dari sistem. Kegagalan yang lebih sulit akan menyebabkan kehilangan informasi dari sistem. Jenis kegagalan yang akan dibahas hanyalah jenis kegagalan berikut :

a. Kegagalan transaksi : Ada dua jenis error yang dapat menyebabkan kegagalan pada transaksi, yaitu :
1. Logical error: Transaksi tidak dapat dilanjutkan pada eksekusi normalnya yang disebabkan kondisi internal, seperti input yang tidak baik, data tidak ditemukan, atau melewati batas kapasitas.

2. Sytem error: Sistem memmasuki suatu status yang tidak diinginkan (sebagai contoh, deadlock), hasilnya transaksi tidak dapat dilanjutkan dengan eksekusi normal. Transaksi yang mengalami kejadian seperti ini kemudian, dapat dieksekusi ulang.

3. Sistem Crash : Ada suatu perangkat keras mengalami kegagalan pemakaian, atau adanya kutu busuk(bug) dalam perangkat lunak database atau sistem operasi, yang dapat menyebabkan hilangnya informasi dari penyimpanan yang mudah hilang(volatile storage), dan menyebabkan proses transaksi berhenti. Isi dari penyimpanan yang tidak mudah hilang (novolatile storage) tetap utuh, dan tidak dirusak.

Asumsi bahwa kesalahan perangkat keras dan kutu busuk(bug) dalam perangkat lunak membuat sistem berhenti,tetapi tidak merusak isi dari penyimpanan non-volatile, hal ini dikenal dengan asumsi fail-stop. Sistem desain yang baik mempunyai cek internal yang banyak, pada level perangkat lunak dan level perangkat keras, yang membawa sistem untuk berhenti ketika terjadi error. Karenanya, asumsi fail-stop adalah satu hal yang layak.

b. Disk Failure : Suatu blok disk kehilangan isinya sebagai salah satu hasil dari head yang crash atau kegagalan selama operasi memindahkan data. Copian data pada tempat penyimpanan lain, atau backup arsip pada media ketiga, seperti tape, dapat digunakan untuk memperbaiki dari kegagalan.

Untuk menentukan bagaimana sistem harus tersembuhkan dari kegagalan, dibutuhkan identifikasi mode kegagalan dari peralatanperalatan yang digunakan untuk menyimpan data. Berikutnya,harus mempertimbangkan bagaimana mode kegagalan ini mempengaruhi isi dari database. Kemudian mengusulkan jenis algoritma yang dapat memastikan bahwa konsistensi database dan atomicity transaksi dapat mengatasi kegagalan. Algoritma tersebut dikenal dengan algoritma recovery, dan mempunyai dua bagian penting, antara lain :

c. Tindakan yang dilakukan selama proses transaksi berjalan normal untuk memastikan bahwa ada cukup informasi yang diijinkan untuk direcovery dari kegagalan.

d. Tindakan yang dilakukan setelah kegagalan direcovery isi database dapat dipastikan telah konsisten, atomicity transaksi, dan durablitasnya, [Silberschatz,2017, "Database Sistem Consept"].

Sistem database secara permanent berada dalam penyimpanan non-volatile(disk), dan dibagibagi menjadi unit penyimpanan fixed-length yang disebut block. Block adalah unit transfer data dari dan ke Disk, yang mungkin masih berisi beberapa 
item data. Cara pengaksesannya ditunjukkan pada gambar 1. Berikut :

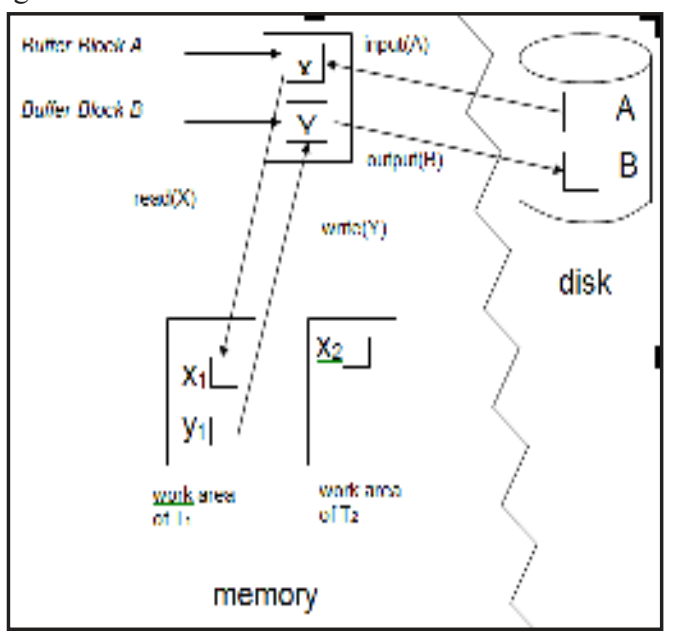

Gambar 1. Contoh pengaksesan data Atomicity dan Recovery

\subsection{Recovery Berbasis Log}

Ada beberapa jenis rekaman log, update log record yang menggambarkan penulisan database tunggal, yang mempunyai field-field :

a. pengenal transaksi

b. pengenal item data

c. nilai lama

d. nilai baru

Record log khusus yang digunakan untuk merekam peristiwa penting selama proses transaksi, seperti start transaksi, commit atau Abort(rollback) transaksi ditandai dengan cara merekam log seperti :

1. $<\mathrm{T}_{\mathrm{i}}$ start $>$, transaksi $\mathrm{T}_{\mathrm{i}}$ dimulai

2. $<\mathrm{T}_{\mathrm{i}}, \mathrm{X}_{\mathrm{j}}, \mathrm{V}_{1}, \mathrm{~V}_{2}>$, Transaksi $\mathrm{T}_{\mathrm{i}}$ melakukan Write item data $X_{j} . X_{j}$ mempunyai nilai $V_{1}$ sebelum Write, dan akan mempunyai nilai $\mathrm{V}_{2}$ setelah Write.

3. $<\mathrm{T}_{\mathrm{i}}$ commit $>$, Transaksi $\mathrm{T}_{\mathrm{i}}$ dicommit

4. $<\mathrm{T}_{\mathrm{i}}$ Abort/Rollback $>$

Eksekusi transaksi $T_{i}$ berproses sebagai berikut, sebelum $T_{i}$ start dieksekusi, record dari $<T_{i}$ start $>$ ditulis ke log. Operasi write( $\mathrm{x})$ oleh $\mathrm{T}_{\mathrm{i}}$, menghasilkan record baru pada log. Akhirnya, ketika $\mathrm{T}_{\mathrm{i}}$ commit sebahagian, record $<\mathrm{T}_{\mathrm{i}}$ commit $>$ ditulis kedalam log. Sistem bank sederhana melakukan transaksi $\mathrm{T}_{0}$ transfer dana dari rekening A ke B :

$\mathrm{T}_{0}: \operatorname{read}(\mathrm{A})$;

$\mathrm{A}:=\mathrm{A}-50$;

$\operatorname{read}(\mathrm{B})$

$\mathrm{B}:=\mathrm{B}+50$;

write(B), kemudian transaksi $\mathrm{T}_{1}$, menarik dana $\$ 100$ dari rekening $\mathrm{C}$ :

$\mathrm{T}_{1}: \operatorname{read}(\mathrm{C})$;

$\mathrm{C}:=\mathrm{C}-100$;

Write(C);

Transaksi dieksekusi secara serial, rekening masingmasing $\mathrm{A}=\$ 1000, \mathrm{~B}=\$ 2000$ dan $\mathrm{C}=\$ 700$ sebelum transaksi dieksekusi. Porsi dari log relevant yang berisi informasi atas kedua transaksi ini nampak pada gambar 2.

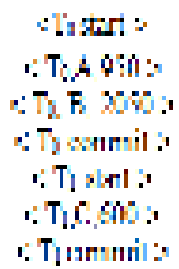

Gambar.2 Porsi log database sesuai dengan transaksi $T_{0}$ dan $\mathrm{T}_{1}$

\section{ANALISA MASALAH}

\subsection{Skema Database}

Skema merupakan kumpulan/ koleksi dari data tertentu dengan menggunakan model data dan menyatakan hubungan antar atribut beserta urutannya. Skema memberikan deskripsi logik secara lengkap dari basis data, termasuk didalamnya nama dan deskripsi dari semua rincian data, record, set dan area untuk semua aplikasi yang menggunakan basisdata tersebut [ Date, 2001]. Skema digunakan sebagai persiapan pembuatan tabel,skema yang dapat dimunculkan dari tabel-tabel yang digunakan pada sistem bank penelitian ini adalah sebagai berikut :

a. Skema untuk Nasabah :

Skema Nasabah = (No_Rek Char(10), Nama Varchar(30) not null, Pin ${ }^{-} \operatorname{Varchar}(12)$ not null, Alamat Varchar(30) not null, Tgl_Daftar Datetime,Saldo Money not null, Aktif Integer, Primary Key ( No_Rek));

b. Skema untuk Simulasi/Transaksi :

Skema Transaksi $=$ (No Rek Char(10), Id_Transaksi Integer(4) not null, Tgl_Transaksi DateTime not null, Jml_Transaksi Money not null, Saldo Money not null, Foreign Key(No_Rek) Reference Nasabah, Foreign Key(Id_Transaksi) Reference Jenis_Transaksi, Keterangan Char(20) );

c. Skema untuk Jenis_Transaksi :

Skema Jenis_Transaksi $=$ (Id_Transaksi Integer(4),Nama_Transaksi $\operatorname{VarChar}(20)^{-}$not null, Jenis_Transaksi ${ }^{-}$Char(1) not null, Primary Key(Id_Transaksi));

\subsection{Implementasi}

Kapasitas Hardisk Sebelum Ujicoba system $=2.25$ MB data dan $65.8 \mathrm{Mb}$ log

Selama Pengujian system dilakukan diperoleh hasil percobaab sebagai berikut:

\section{a. 1000 Transaksi}

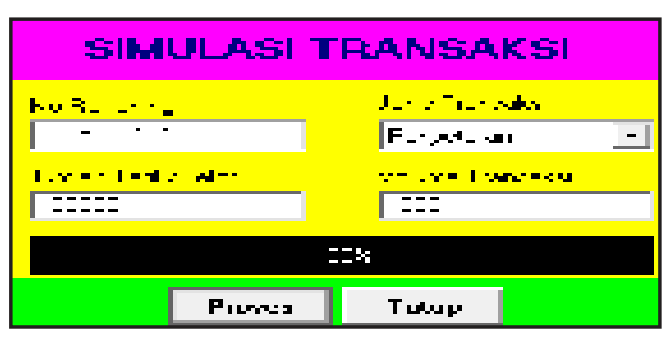

Gambar 3. Tampilan Simulasi 1000 Transaksi Hasilnya :

Data $=2.359 \mathrm{Mb}$

$\log =69.074 \mathrm{MB}$ 


\section{b. 10000 Transaksi}

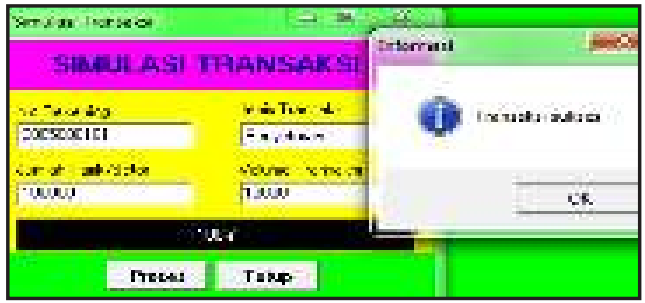

Gambar 4. Tampilan Simulasi 10000 Transaksi

Hasilnya :

Data $=3.145 \mathrm{Mb}$

$\log =69.074 \mathrm{MB}$

\section{KESIMPULAN}

Setelah dilakukan uji coba terhadap simulasi transaksi untuk menganalisa pengaruh log transaksi pada system berbasis computer dapat diambil kesimpulan sebagai berikut:

1. Volume transaksi 1000 hardisk mengalami perubahan kapasitas dari $2.25 \mathrm{MB}$ menjadi 2.359 $\mathrm{Mb}$.

2. Volume transaksi 10000 hardisk mengalami perubahan kapasitas dari $2.359 \mathrm{Mb}$ menjadi $3.145 \mathrm{Mb}$.

3. Volume transaksi 10000 hardisk mengalami perubahan kapasitas dari 2.359 Mb menjadi $3.145 \mathrm{Mb}$.

1. Algoritma Apriori dapat membantu mengembangkan strategi pemasaran dengan memberikan saran kepada konsumen.
2. Pengimplementasian Algoritma Apriori pada tanagra dimulai dengan penginputan data pesanan perbulan yang menjadi database pada Ms.Excel, semakin banyak data maka pembuatan tabel tabular akan semakin sulit. Tabel tabular tersebut yang kemudian dikoneksikan ke dalam tools tanagra, dan mulailah pembentukan support dan confidence dan kemudian akan menghasilkan asosiasi final yang memenuhi support dan confidence .

\section{REFERENSI}

[1] Fricles Ariwisanto Sianturi. Penerapan Metode Contrast Stretching Untuk Peningkatan Kualitas Citra Bidang Biomedis. $J$ Mantik Penusa. 2015;18(2):70-75. http://ejurnal.pelitanusantara.ac.id/index.php/mantik/article /view/132.

[2] Jenn - Wei Lin and Sy-Yen Kuo, (September 8,2010)," A New Log -Based approach to Independent Recovery in Distributed Shared Memory(DSM) System", Departement of Electrical Engineering, National Taiwan University, Taipei.

[3] Yulianto, F.,2003," Pemanfaatan Microsoft Transaction Server(MTS) dalam Sistem Informasi Kepegawaian dan Keuangan", tesis Program Pasca Sarjana Ilmu Komputer UGM Yogyakarta

[4] Fricles Ariwisanto Sianturi. Penerapan Metode Contrast Stretching Untuk Peningkatan Kualitas Citra Bidang Biomedis. $J$ Mantik Penusa. 2015;18(2):70-75. http://ejurnal.pelitanusantara.ac.id/index.php/mantik/article /view/132. 